Groothuis, Peter A., Hill, J. Richard. (2004) Exit Discrimination in the NBA: A Duration Analysis of Career Length, Economic Inquiry, Vol. 42(2):341-349 (April 2004). Published by Wiley-Blackwell (ISSN: 0095-2583).

\title{
Exit Discrimination in the NBA: A Duration Analysis of Career Length
}

\author{
Peter A. Groothuis, Richard J. Hill
}

\begin{abstract}
Using a panel study of annual NBA data (1989-99), evidence of exit discrimination on career length in the NBA is not found. This result is inconsistent with results from data in the 1980s but is consistent with more recent findings that have measured wage discrimination in sports in the 1990s. In a semiparametric duration analysis, it is found that performance variables are important in determining career length. These results suggest that team owners in the pursuit of championships keep talented players regardless of race. This is an affirmation of Becker's theoretical implications of market competition on discrimination.
\end{abstract}




\section{INTRODUCTION}

In the National Basketball Association (NBA), as in most professional sports leagues, player turnover is high from season to season due to declining skills as players age. In our analysis, we ask: Are there any factors that determine the duration of players with any consistency? Is the position in which a player was selected in the draft a significant indicator of duration`? Is there any exit discrimination in the career duration where black players have shorter careers than white players?

We examine the determinants of player duration using data covering the 1989-99 period. The data include individual player performance statistics on a season-to-season basis as well as biographical player data on height, weight, race, and draft number. Our model differs from the only previous study on duration in the NBA in that our estimation technique allows for the use of a mixed stock and flow sample. Our time period is also longer than the previous study.

\section{Literature Review}

Sports economics has provided a rich field of study for labor economists to explore issues of discrimination. Professional baseball has attracted much of the attention of researchers. Scully (1974) found evidence of barriers to entry for black athletes in professional baseball using data from 1960-71 and evidence of pay discrimination using data from the late 1960s. Hill and Spellman (1984) found no evidence of pay discrimination or barriers to entry using data from the 1976--77 period. Subsequent studies with later data confirmed the lack of discrimination in baseball. Cymrot (1985) suggested that free agency was responsible for this turn of events; according to Kahn $(1991,402)$ the reasons for the reversal of outcomes are unclear.

Kahn and Sherer (1988) were the first to offer credible evidence of salary discrimination against African American professional basketball players. Despite $75 \%$ of the players in the league being black, data from regressions using 1985-86 salaries suggested a $20 \%$ shortfall in compensation for African American players, ceteris paribus. The results of other researchers using data from the same time period confirmed the conclusions. The source of the discrimination was found to be fans by Kahn and Sherer (1988, 56-57), Burdekin and Idson (1991), and Brown et al. (1991, 337). Again, however, just as in the case for baseball, studies by Hamilton (1997), Dey (1997), and Gius and Johnson (1998) with newer salary data failed to find evidence of salary discrimination in the NBA. Despite these findings, Kanazawa and Funk (2001) still found the existence of customer discrimination in the cable television Nielsen ratings during the 1996--97 season.

In addition to salary discrimination, labor economists have focused on both entry and exit discrimination. For instance, Kahn and Sherer (1988, 53-55) found no evidence of hiring discrimination in the NBA, but Brown et al. (1991, 339-43) found only weak evidence that black players had to outperform whites for entry into the league. In addition, Johnson and Marple (1973) using data from 1970 and Hoang and Rascher $(1999,78)$ using data from the 1980s, both find evidence that white players have a lower probability of being cut from the league. Hoang and Rascher (1999, 87-88) find that the effect of "exit discrimination" on career earnings in the NBA is larger than the effects of the previously documented wage discrimination. 
The problem with both of the previous studies on exit discrimination is that neither has the ability to analyze long careers in the NBA. For instance, the Johnson and Marple study only analyzed the career of benchwarmers in the 1970 season. Hoang and Rascher use a panel study of flow data that only allows for career length up to nine years, the length of their panel. In our study, we analyze exit discrimination by utilizing a combination of stock and flow sample data from the 1990s that allows us to address both long and short careers.

\section{Discrimination Theory}

Minority workers may be discriminated against by being paid a lower wage, having more difficulty finding a job, or having a lower probability of retention than those of the majority workers for comparable productivity. In the case of discrimination due to personal prejudice, Becker (1971) notes that the source of personal prejudice is an important determinant of whether the discrimination will last.

According to theory, wage differentials and workplace segregation resulting from prejudice by employers and co-workers will dissipate over time in a competitive environment. In sports, free agency, the presence of sufficiently qualified minority workers, some nonprejudiced owners and fellow players, and the desire to maximize profits and or win championships should alleviate the discrimination arising from these sources.

If the source of the personal prejudice is customers, however, the existence of wage discrimination, exit discrimination, and/or segregation may be more difficult to eradicate. Employers are responding to profit motivation in the marketplace by discriminating in this instance, and competition may not improve the situation. In sports, researchers have long suspected that prejudice by fans is present. Scully (1974) suggested that blacks were relegated to outfield positions because they would be further away from the more expensive seats and the focus of TV cameras. Kanazawa and Funk (2001), using Nielsen ratings from the 1996-97 season, find that the presence of a white player on a team increases TV ratings that translate into more advertising revenues.

Hoang and Rascher ( 1999, 74-75) postulate the desire of white fans to see white players may mean the existence of exit discrimination. According to their reasoning, as owners seek to satisfy the discriminatory tastes of the majority white customers they reserve a minimum number of roster spots for white players. They further suggest that there is a dwindling supply of white rookies who can play at the professional level. Thus fans' taste for white players and a dwindling supply of white rookies suggests that an existing white player will enjoy a longer career than their black counterpart with similar performance levels.

To capture the essence of the customer discrimination model, we suggest that exit can be modeled as a function of both talent and race. Team owners in the pursuit of profits desire talent because fans follow winning teams and team owners desire white players because white players bring white fans. 


\section{THE MODEL}

Our data include all individuals who participated in the NBA from 1989 through 1999 for an 11year panel consisting of 1113 players. To capture the overall length of players' NBA careers our data consists of both stock and flow samples (see Figure 1). A stock sample consists of all ongoing careers at the start of the panel in 1989. These left-censored data are easily included because we know how many years each player had played in the NBA prior to 1989. Our stock sample consists of 295 players who had an average tenure of 6.01 years as they entered the 1989 season. Including a stock sample captures information on players whose careers are longer than the panel data set. For instance, one player during the 1990s had a career length of 21 years. Using only stock data, however, would underrepresent short-career players, so we also include flow data.

A flow sample includes all careers that start between 1989 and 1999. This sample captures many short careers in the NBA. For instance, during the 1990s 134 players had one-year careers. Including only flow data, however, would allow for no careers longer than 11 years, which is the length of our panel. As with most panels, our data is also rightcensored, where many careers were ongoing when our sample ended in 1999. Our rightcensored data include both stock and flow observations. To estimate a duration model of stock and flow data, we use a technique developed by Berger and Black (1999).

The variables in our data include both season-variant and season-invariant data. We report the means in Table 1. Our seasoninvariant data include the player's height, weight, race, and draft number. We find that the average height in the NBA is six feet, seven inches; average weight is 221 pounds; and $21 \%$ of the players are white. Our seasonvariant data are performance data that include games played per season as well as assists, rebounds, steals, turnovers, blocked shots, and points all calculate per minute played over the season. We report the means by the race of the player. We find that white players are on average 2 inches taller and 14 pounds heavier. White players also on average play five fewer games per season than black players. The average career length as measured by all nonright-censored data is 6 years for whites and 5.5 years for blacks. To determine if exit discrimination exits in the NBA, we analyze the data using both nonparametric and semiparametric techniques.

\section{Nonparametric Estimates of Career Duration}

To help understand career duration in the NBA, we calculate yearly hazard functions as 


$$
h_{t}=d_{t} / n_{t} \text {, }
$$

where $d_{t}$ is the number of players who end their career in year $t$, and $n_{t}$ is the number of players at risk of ending their career in year $t$. The hazard rate can be interpreted as the percentage of players who exited the NBA given they have survived up to some level of tenure. In Table 2, we report the total hazard rate and the hazard rate for both black and white players.

In Figure 2 we plot the hazard functions by race, where series one is the hazard rate for black players and series two the hazard rate for white players. Both plots show that the hazard rate gradually declines for the first seven years of tenure in the NBA and then gradually climbs for the remainder of the years. In addition both hazard plots follow an interesting pattern that resembles a u shape. In the engineering literature on useful life, this hazard function shape has become known as the bath- 
TABLE 2

NBA Hazard Rates

\begin{tabular}{rlll}
\hline Tenure & Total & Black & White \\
\hline 1 & 0.182 & 0.185 & 0.167 \\
2 & 0.146 & 0.138 & 0.176 \\
3 & 0.134 & 0.129 & 0.155 \\
4 & 0.102 & 0.095 & 0.129 \\
5 & 0.102 & 0.098 & 0.120 \\
6 & 0.079 & 0.091 & 0.031 \\
7 & 0.061 & 0.048 & 0.103 \\
8 & 0.108 & 0.100 & 0.136 \\
9 & 0.097 & 0.084 & 0.140 \\
10 & 0.158 & 0.154 & 0.174 \\
11 & 0.175 & 0.153 & 0.250 \\
12 & 0.153 & 0.156 & 0.143 \\
13 & 0.242 & 0.243 & 0.238 \\
14 & 0.243 & 0.192 & 0.428 \\
15 & 0.200 & 0.216 & 0.125 \\
16 & 0.200 & 0.142 & 0.500 \\
17 & 0.214 & 0.231 & 0 \\
18 & 0.500 & 0.428 & 1.00 \\
19 & 0.333 & 0.333 & - \\
20 & 0 & 0 & - \\
21 & 1 & 1 & - \\
\hline
\end{tabular}

FIGURE 2

Hazard Rate

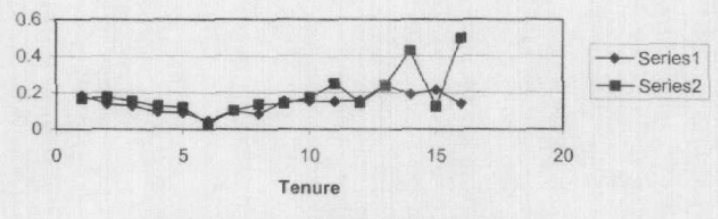

Series 1=Black hazard rate, Series $2=$ White hazard rate.

tub plot. In this literature, the initial downturn is identified as infant mortality, the bottom of the tub due to random failure, and the upturn due to wear-out (Bolla 2002). We suggest that this pattern also explains an NBA career with the initial downturn occurring as individuals are sorted from the league and the upturn due to wear-out from the physical demands of playing basketball.

Comparing the two plots shows many crosses. The hazard plot suggests that the hazard rates for both black and white players are similar. Interpreting the differences in hazard rates as discrimination, however, is misleading. The problem arises for the same reason using differences in median wage is misleading in the wage literature: neither method controls for differences due to productivity. In the next section we analyze career duration using semiparametric techniques to control for differences in productivity.

\section{Semiparametric Estimates of Career Duration}

We estimate semiparametric hazard functions following Berger and Black (1999) and Berger et al. (2001). Because our data are at the season level, we calculate our hazard model as a discrete random variable. As with Black et al. (2001), we model the durations of a single spell and assume a homogeneous environment so that the length of the spell is uncorrelated with the calendar time in which the spell begins. This assumption lets us treat all the players' tenure as the same regardless of when it occurred in the panel study. For instance, all fourth-year players are considered to have the same baseline hazard regardless of calendar time, so a fourth-year player in 1990 has the same baseline hazard as a fourth-year player in 1997.

To understand how stock data influence a likelihood function, we follow the notation of Berger et al. (2001). Suppose the probability mass function (PMF) of durations is defined as

$$
f(t, x, \beta),
$$

where $t$ is the duration of the career, $x$ is a vector of performance and personal characteristics, and $\beta$ is a vector of parameters. Now denote $F(t, x, \beta)$ as the cumulative distribution function; then the probability that a career lasts at least $t^{0}$ years is simply $1-F\left(t^{0}, x, \beta\right)$. If we define the hazard function as $h(t, x, \beta) \equiv f(t, x, \beta) /$ $S(t, x, \beta)$ and apply the definition of conditional probabilities, we may express the PMF as

$$
f\left(t_{i}, x_{i}, \beta\right)=\prod_{j=0}^{t_{i}-1}\left[1-h\left(j, x_{i}, \beta\right)\right] h\left(t_{i}, x_{i}, \beta\right)
$$

If we have a sample of $n$ observations, $\left\{t_{1}, t_{2}, \ldots t_{n}\right\}$, the likelihood function of the sample is 
Often it is not possible to observe all careers until they end, hence careers are often rightcensored. Let set A be the set of all observations where the players' careers are completed and set $\mathrm{B}$ be the set of all observations where the careers are right-censored. In this case, A and B are disjoint sets whose union is exactly the set of observation. For the set of right-censored observations, all we know is that the actual length of the career is greater than $t_{i}$, the observed length of the career up through the last year. Because we know that the actual length of the career is longer than we observe then the contribution of these observations to the likelihood function is just the survivor function, $S\left(t_{i}, x_{i}, \beta\right)$. Thus, we may write the likelihood function as

$$
\begin{aligned}
L(\beta)= & \prod_{i \in A}\left(\prod_{j=1}^{t_{i}-1}\left[1-h\left(j, x_{i}, \beta\right)\right] h\left(t_{i}, x_{i}, \beta\right)\right) \\
& \times \prod_{i \in B} S\left(t_{i}, x_{i}, \beta\right) \\
= & \prod_{i \in A}\left(\prod_{j=1}^{t_{i}-1}\left[1-h\left(j, x_{i}, \beta\right)\right] h\left(t_{i}, x_{i}, \beta\right)\right) \\
& \times \prod_{i \in B}\left(\prod_{j=1}^{t_{i}-1}\left[1-h\left(j, x_{i}, \beta\right)\right]\right) .
\end{aligned}
$$

Equation (5) exploits the property that $S(t, x, \beta)=\prod_{i=1}^{t-1}[1-h(i, x, \beta)]$. Equation (5) is the likelihood function for any flow sample of discrete durations.

To introduce stock sampling, let set $\mathrm{C}$ be the set of careers that were in progress when data collection began. For these observations, we know that the career $i$ has lasted for $r$ years before the panel begins, so that the probability that the total career length will be $t$ is simply given by

$$
\begin{aligned}
& f(t, x, \beta) / S(r, x, \beta) \\
& \quad=\left(\prod_{i=r}^{t-1}[1-h(i, x, \beta)]\right) h(t, x, \beta) .
\end{aligned}
$$

Because we are sampling careers that are already in progress, these observations enter the sample only if the career is at least of length $r$, hence we must adjust by the conditional probability of the career having length $r$. With the addition of these observations, we may write the likelihood function as

$$
\begin{aligned}
L(\beta)= & \prod_{i \in A}\left(\prod_{j=1}^{t_{i}-1}\left[1-h\left(j, x_{i}, \beta\right)\right] h\left(t_{i}, x_{i}, \beta\right)\right) \\
& \times \prod_{i \in B}\left(\prod_{j=1}^{t_{i}-1}\left[1-h\left(j, x_{i}, \beta\right)\right]\right) \\
& \times \prod_{i \in C}\left(\prod_{j=r_{i}}^{t_{i}-1}\left[1-h\left(j, x_{i}, \beta\right)\right]\right) h\left(t_{i}, x_{i}, \beta\right) .
\end{aligned}
$$

The third term of the right-hand side of equation (7) reflects the adjustment necessary for the stock sample that end during our panel. Because stock-sampled observations, by definition, must have survived until tenure $r$, that they survived until time $r$ provides no information; their survival is an artifact of the sampling strategy.

Of course, some stock-sampled observations may be right-hand-censored. Let set D be the set of all stock-sampled observations that are also right-hand-censored. An example of a career that is both right- and left-censored would be a player that starts his career prior to 1989 and ends his career after 1999. A stocksampled observation that is right-handcensored at time $t$ occurs with probability

$$
S(t, x, \beta) / S(r, x, \beta)=\prod_{j=r}^{t-1}[1-h(j, x, \beta)]
$$

so that the likelihood function becomes

$$
\begin{aligned}
L(\beta)= & \prod_{i \in A}\left(\prod_{j=1}^{t_{i}-1}\left[1-h\left(j, x_{i}, \beta\right)\right] h\left(t_{i}, x_{i}, \beta\right)\right) \\
& \times \prod_{i \in B}\left(\prod_{j=1}^{t_{i}-1}\left[1-h\left(j, x_{i}, \beta\right)\right]\right) \\
& \times \prod_{i \in C}\left(\prod_{j=r_{i}}^{t_{i}-1}\left[1-h\left(j, x_{i}, \beta\right)\right]\right) h\left(t_{i}, x_{i}, \beta\right) \\
& \times \prod_{i \in D}\left(\prod_{j=r_{i}}^{t_{i}-1}\left[1-h\left(j, x_{i}, \beta\right)\right]\right)
\end{aligned}
$$

In equation (9), the contribution of censored, stock-sampled observations to the likelihood function is strictly from the last 
two terms; such observations simply provide information about the survivor function between $(r, t)$.

Thus we, like Berger et al. (2001), have expressed the likelihood function as a function of the hazard functions. All that remains is to specify the form of a hazard function and estimate by means of maximum likelihood estimation. Because the hazard function is the conditional probability of exiting the NBA given that the NBA career lasted until the previous season, the hazard function must have a range from zero to one. In principle, any mapping with a range from zero to one will work. Cox (1972) recommends

$$
\begin{aligned}
& h(t, x, \beta) /[1-h(t, x, \beta)] \\
& \quad=\left(h_{t} / 1-h_{t}\right) e^{x \beta}=\exp \left(\gamma_{t}+x \beta\right),
\end{aligned}
$$

which is simply the logit model with intercepts that differ by time periods. The term $h_{t}$ is a baseline hazard function, which is common to all. The $x \beta$ term, determined by the player's personal and productivity characteristics, shifts the baseline hazard function, but it affects it in exactly the same way each period. Berger and Black (1999) consider other hazard functions and find that the results are relatively robust across various specifications of the hazard function. The logit model is available in many software packages, so we follow Cox and use the logit model.

The intuition behind equation (10), when using the logit model for the hazard function, is relatively simple. For each year during the survey in which the player is in the NBA, the player either comes back for another season or ends his career. If the career ends, the dependent variable takes on a value of one; otherwise, the dependent variable is zero. The player remains in the panel until he exits the NBA or the panel ends. If the panel ends, we say the worker's spell is right-hand-censored. Thus a player who begins his NBA career during the panel and plays for six years will enter the data set six times: the value of his dependent variable will be zero for the first five years (tenure one through five) and be equal to one for the sixth year.

To illustrate a stock sample, consider another player who enters the panel with seven years of NBA job tenure prior to 1989 the first year of the panel, then plays for an additional three years for a ten-year career. For this player, we ignore his first seven years of tenure because he is left-hand-censored. As the equation of the likelihood function with stock data indicates, the duration of a NBA career prior to the beginning of the panel makes no contribution to the value of the likelihood function. Therefore, only years eight through ten will enter the data set with the dependent variable taking on the value zero for year eight and nine, and in the tenth year it takes on a value of one, with this player appearing in the data set a total of three times. Note for all players who are right-hand-censored, we do not know when their career ends, so their dependent variables are always coded as zero.

Because the players in the panel have varying degrees of job tenure prior to the beginning of the panel, we identify the hazard function for both long and short careers. The disadvantage to this approach is that the vector $\gamma_{t}$ of equation (10) can be very large. In our study it would require 21 dummy variables. We also run into problems with the Cox technique because we have too few players who have long careers. To simplify the computation of the likelihood function and be able to keep the long careers, we simply approximate the $\gamma_{t}$ vector with a fourth-order polynomial of player's tenure, which reduces the number of parameters to be estimated from 21 to 4 . Thus, the hazard function becomes

$$
\begin{aligned}
& h(t, x, \beta) /[1-h(t, x, \beta)]=\Phi(t) e^{x \beta} \\
& \quad=\exp (\phi[t]+x \beta),
\end{aligned}
$$

where $\phi(t)$ is a fourth-order polynomial in the worker's tenure. Once again, we choose the Taylor series approximation technique over using tenure dummies due to the small number of observations for high tenures. This method provides a very flexible specification of the baseline hazard but does impose more restrictions than Cox's model. ${ }^{1}$

In Table 3, we report the estimates for equation (12) using three different specifications. In model 1 , the complete specification, we find that the tenure polynomials are jointly significant. Second, we find that weight is negative and significant, indicating that heavier players have longer careers than smaller players do.

1. When higher-order polynomials of the fifth and sixth power are included, results do not change, suggesting that a fourth-order polynomial is flexible enough to capture the influence of the baseline hazard. 
TABLE 3

NBA Career Duration Semiparametric Analysis

\begin{tabular}{lcccc}
\hline Variable & Model 1 & Model 2 & Model 3 & Model 4 \\
\hline Constant & $0.794(0.48)$ & $2.88(1.88)$ & $0.646(2.01)$ & $1.93(0.76)$ \\
Tenure* & $-0.029(0.19)$ & $-0.046(0.25)$ & -0.0540 .30 & $1.01(1.37)$ \\
Tenure squared* & $-0.0036(0.09)$ & $0.0024(0.06)$ & $0.0013(0.03)$ & $-0.365(1.24)$ \\
Tenure cubed* & $0.0015(0.47)$ & $0.0012(0.38)$ & $0.0012(0.37)$ & $0.046(1.05)$ \\
Tenure fourth power* & $-0.00006(0.64)$ & $-0.00005(0.56)$ & $-0.00005(0.56)$ & $-0.00203(0.92)$ \\
White & $0.078(0.64)$ & $0.052(0.43)$ & $0.011(0.09)$ & $0.049(0.28)$ \\
Height & $0.032(1.27)$ & $-0.028(1.50)$ & - & $-0.020(0.52)$ \\
Weight & $-0.012(3.76)$ & - & $-0.003(0.62)$ \\
Games & $-0.046(21.30)$ & $-0.047(21.41)$ & $-0.047(21.41)$ & $-0.050(15.35)$ \\
Draft number & $0.0027(3.09)$ & $0.0029(3.28)$ & $0.0031(3.49)$ & $0.0036(3.39)$ \\
Assists & $-2.72(2.69)$ & $-2.01(2.04)$ & $-1.30(1.52)$ & $-2.89(1.92)$ \\
Rebounds & $-0.64(1.01)$ & $-1.15(1.83)$ & $-1.49(2.51)$ & $-0.28(0.39)$ \\
Steals & $-2.65(1.37)$ & $-2.31(1.21)$ & $-2.00(1.05)$ & $-2.56(1.15)$ \\
Blocks & $-3.81(1.80)$ & $-3.91(1.80)$ & $-4.99(2.24)$ & $-3.17(1.42)$ \\
Points & $-0.592(1.88)$ & $-0.569(1.77)$ & $-0.576(1.79)$ & $-0.718(1.69)$ \\
Turnovers & $-0.0008(0.61)$ & $-0.0007(0.60)$ & $-0.0008(0.57)$ & $-0.0127(0.12)$ \\
Likelihood function & -1353.04 & -1360.36 & -1361.45 & -726.56 \\
\hline
\end{tabular}

Notes: Model 1 full specification. Model 2 weight excluded specification. Model 3 weight and height excluded specification. Model 4 flow sample only specification.

*Jointly significant. First-through fourth-order tenure polynomials included to provide for general functional form of baseline hazard. The numbers in parentheses are $t$-ratios.

We find that height has an insignificant effect on career length. Height and weight, however, are highly correlated with a correlation of $70 \%$. In model 2, we exclude weight and find that height becomes negative. ${ }^{2}$ This suggests that quickness and speed depreciate faster than size, showing that big men are predicted to have longer careers in the NBA than small men.

In our model of exit, we suggest that performance should increase career length. Owners will keep players who are productive. All our specifications results support this prediction, where we find performance measures are important in career duration. In particular the number of games played in a season, the number of assists per minute, blocks per minute, and points per minute all increase the likelihood of remaining in the NBA for another season. We also find that draft number determines career length; players with higher draft numbers have shorter careers even after controlling for performance measures.

In our model of exit, we also suggest that race may play a role if white customers have a

2. In an additional specification when weight and height were interacted the interaction term was significant. All specifications suggest that size matters in career duration. preference to see white players and teams find it difficult to replace white players. Our results, however, do not support this claim. We find that our race dummy variable is not statistically significant, indicating that no exit discrimination in the 1990s. To convert the coefficient into a percentage and focus on the magnitude of the effect we use $100[\exp (\beta)-1]$. This conversion gives us the percentage difference in hazard rates between whites and black. Using this method we find that white players have an $8 \%$ higher hazard rate than blacks in the league. This result suggests that white players are more likely to be cut than black players, although the result is statistically insignificant. This result is counter to exit discrimination that was found in the 1980s by Hoang and Rascher (1999), who find that whites have a $36 \%$ lower hazard rate. In the next section, we explore why our results are counter to the Hoang and Rascher result.

\section{Exit Discrimination in the NBA in the $1980 \mathrm{~s}$ and $1990 \mathrm{~s}$}

In this section of our research, we further investigate why Hoang and Rascher (1999) find exit discrimination and we do not. We offer three hypotheses that would account for the 
difference. First, we use a technique that allows for a mixed stock and flow sample that allows for longer tenure spells in the NBA. We suggest that maybe discrimination exists for short careers but not long careers. Second, we include height and weight variables, and they do not. We suggest that their race variable may serve as a proxy for size differences that play a role in career duration. Third, our study uses data from the $1990 \mathrm{~s}$, whereas their data are from the 1980s. We suggest, as with other more recent studies, that discrimination is no longer detected in professional sports leagues.

Although we cannot explore why the difference exists using their data set, we explore the differences using our data set. To test hypothesis one, that discrimination exists for short careers, we estimated our model using only the flow sample. The flow specification is reported as model 4 in Table 3 . In this specification the race coefficient was positive and insignificant, indicating that even when focusing only on short careers, we do not find discrimination. To test hypothesis two, we estimated our model excluding both weight and height variables. This specification is reported as model 3 in Table 3. Again, we found the coefficient on the race dummy insignificant. This result suggests that race does not serve as a proxy for player size. We therefore suggest that the exit discrimination may have existed in the 1980s but did not exist for players in the 1990s.

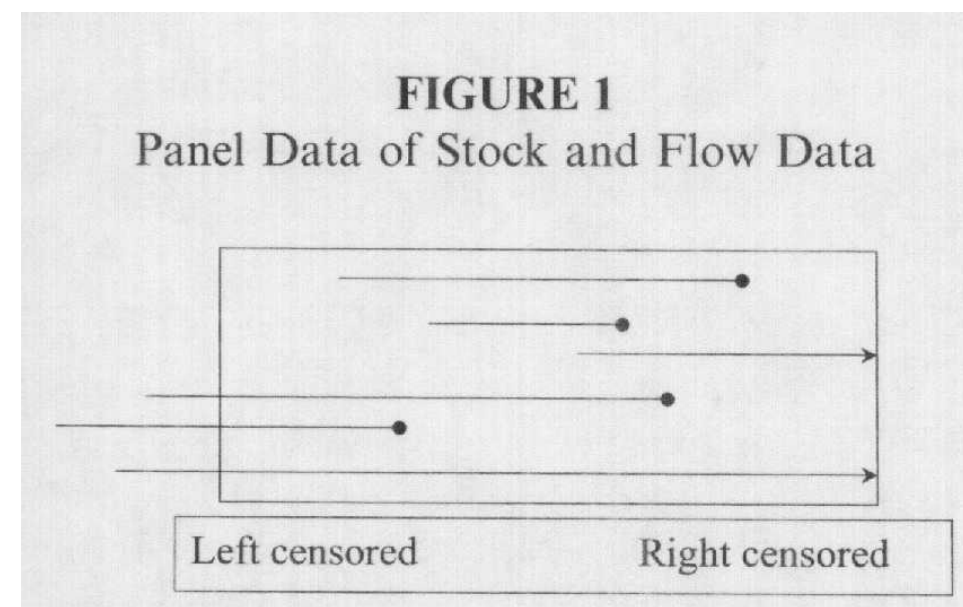




\section{TABLE 1}

NBA Panel Data: Means of Variables

\begin{tabular}{lccc}
\hline Variables & Means & White & Black \\
\hline Tenure* (years) & 5.72 & 5.92 & 5.47 \\
White** (\%) & 0.205 & - & - \\
Height** (inches) & 79.08 & 80.68 & 78.48 \\
Weight** (pounds) & 221 & 230 & 216 \\
Field goals*** (\%) & 44.1 & 44.1 & 44.1 \\
Free throws*** (\%) & 70.2 & 70.1 & 70.2 \\
Games*** (number) & 54.5 & 50.6 & 55.4 \\
Assists*** (per min) & 0.086 & 0.080 & 0.087 \\
Rebounds*** (per min) & 0.177 & 0.187 & 0.173 \\
Steals*** (per min) & 0.034 & 0.029 & 0.035 \\
Turnovers*** (per min) & 0.076 & 0.061 & 0.079 \\
Blocked shots*** & 0.021 & 0.022 & 0.021 \\
(per min) & & & \\
Points*** (per min) & 0.381 & 0.362 & 0.385 \\
Individuals & 1113 & 219 & 824 \\
Panel length & 11 years & & \\
Observations & $(89-99)$ & & \\
\hline & 4476 & 918 & 3458 \\
\hline
\end{tabular}

* Length of career for all non-right-censored data.

**Time-invariant data calculate using individual data.

***Time-variant data calculate using observational data.

\section{IMPLICATIONS OF THE RESULTS IN A GENERAL CONTEXT}

Hoang and Rascher (1999) suggested that the effect on career earnings of exit discrimination was over twice as large as the effect of pay discrimination in the 1980s. The apparent disappearance of pay discrimination from the NBA in the 1990s would not mean an end to unequal career earnings if exit discrimination persisted. Our results indicate that exit discrimination no longer exists in the NBA.

The importance of these results extends beyond the courts of the NBA. Kahn (2000) discussed the use of research in the area of professional sports as a laboratory for testing general labor market propositions. Various laws in this country have helped moderate the level of racial pay 
discrimination in the labor market. In contrast to the black economic progress portrayed by Smith and Welch (1989), more recent research suggests that the progress enjoyed by minorities in entry-level positions is not sustained throughout their careers. Sexton and Olsen (1994) find that blacks have acquired less on-the-job training than their white counterparts and that the training they do acquire is not likely to increase their pay. Bratsberg and Terrell (1998) suggest that returns to general experience for black employees trail those for white employees. It is doubtful that legislative means can end such labor market outcomes.

The area of professional sports provides an excellent setting to study the effects of market competition on discrimination outlined by Becker (1971). Most franchises have the stated or purported purpose to win games and/or championships. This objective function may serve to increase attendance and hopefully franchise profits or may satisfy the needs of a sportsman entrepreneur or civic-minded owner seeking to provide a winning team for his or her city. The competition to provide winning teams should eliminate the existence of discrimination in employment. Conflict may arise, however, if the source of discrimination is fans. The results of Kanazawa and Funk (2001) suggest lingering fan discrimination into the mid- to late 1990s. However, although ceteris paribus results may indicate an improvement in attendance and/or TV ratings for an increase in the number of white players on a franchise, particularly in areas with a higher percentage of white population, the management of the franchise must weigh this against the overwhelming impact of winning on attendance.

The lack of exit discrimination found in our study indicates that winning games supersedes even the tastes of fans' racial preferences. These results seem to be a resounding affirmation of Becker's theoretical implications. Outside the realm of professional sports, where objective statistics of employee performance and firm performance are not so readily available, the implications for Becker's model of the findings of unequal promotional attainment and onthe-job training by minorities is unclear. Our results, however, suggest that if competition is present performance on the job may now supersede race as the prime determinant of employee retention.

\section{CONCLUSIONS}

We use a panel study of annual NBA data to examine the exit discrimination on career length in the NBA. We find that performance variables are important determinants in career length where more productive players have longer careers. This result suggests that team owners in the pursuit of championships and profits keep talented players. In our analysis, we also find that big men are predicted to have longer careers than small men. We do not, however, find exit discrimination in the NBA in the 1990s. This result is inconsistent with results from data in the past that has found exit discrimination but is consistent with more recent findings that have measured wage discrimination in sports in the 1990s. 


\section{REFERENCES}

Becker, G. The Economics of Discrimination, -Ind ed. Chicago: University of Chicago Press, 1971.

Berger, M. C.. and D. A. Black. "The Duration of Medicaid Spells: An Analysis Using Flow and Stock Samples." Review of Economics and Statistics, 80(4), 1999, 667-74.

Berger, M. C., D. A. Black, and F. Scott. "The Myth of Job Lock." University of Kentucky Working Paper, 2001.

Bolla, G. A. "Accelerated Useful Life Testing and Field Correction Methods." Visteon Corporation Paper, Society of Automotive Engineers, 2002.

Bratsberg, B., and D. Terrell. "Experience, Tenure, and Wage Growth of Young Black and White Men." Journal of Human Resources, 33(3), 1998, 658-82.

Brown, E., R. Spiro, and D. Keenan, "Wage and NonWage Discrimination in Professional Basketball: Do Fans Affect It?" American Journal of Economics and Sociology, 50, 1991, 33345.

Burdekin, R. C. K., and T. L. Idson. "Customer Preferences, Attendance and the Racial Structure of Professional Basketball Teams." Applied Economics, 23, 1991, 179-86.

Cox, D. R. "Regression Models with Life Tables." Journal of Royal Statistical Society, Series B, $34,1972,187-220$.

Cymrot, D. J. "Does Competition Lessen Discrimination? Some Evidence." Journal of Human Resources, 20(4), 1985,605-12.

Dey, M. S. "Racial Differences in National Basketball Association Players' Salaries: A New Look." American Economist, 41(2), 1997, 84-90.

Gius, M., and D. Johnson. "An Empirical Investigation of Wage Discrimination in Professional Basketball." Applied Economics Letters, 5, 1998, 703--5.

Hamilton, B. H. "Racial Discrimination and Professional Basketball Salaries in the 1990's." Applied Economics, 29, 1997, 287-96.

Hill, J. R., and W. Spellman. "Pay Discrimination in Baseball: Data from the Seventies." Industrial Relations, 23(1), 1984, 103-12.

Hoang, H., and D. Rascher. "The N BA, Exit Discrimination, and Career Earnings." Industrial Relations, 38(1), 1999, 69-91.

Johnson, N. R., and D. P. Marple. "Racial Discrimination in Professional Basketball: An Empirical Test." Sociological Focus, 6(4), 1973, 6-18. 
Kahn, L. M. "Discrimination in Professional Sports: A Survey of the Literature." Industrial and Labor Relations Review, 44(3), 1991, 395-418. - . "The Sports Business as a Labor Market Laboratory." Journal of Economic PersPectives, 14(3), 2000, 75-94.

Kahn, L. M., and P. D. Sherer. "Racial Differences in Professional Basketball Players Compensation." Journal of Labor Economics, 6( ), 1988, 40-61.

Kanazawa, M. T., and J. P. Funk. "Racial Discrimination in Professional Basketball: Evidence from the Nielsen Ratings." Economic Inquiry, 39(4), 2001, 599-608.

Scully, G. W. "Discrimination: The Case of Baseball,' Government and the Sports Business, edited by Roger G. Noll. Washington, DC: Brookings Institution, 1974, 221-74.

Sexton, E. A., and R. Neil Olsen. "The Returns to On-theJob Training: Are They the Same for Blacks and Whites?" Southern Economic Journal, 61(2). 1994, 328-42.

Smith, J. P., and F. R. Welch. "Black Economic Progress after Myrdal." Journal of Economic Literature, 27(2), 1989, 519-64. 